\title{
THE INTERRELATIONS OF SERUM LIPIDS IN PATIENTS WITH DISEASES OF THE KIDNEYS ${ }^{1}$
}

\author{
By JOHN P. PETERS AND EVELYN B. MAN \\ (From the Departments of Internal Medicine and Psychiatry of the Yale University School of \\ Medicine, New Haven)
}

(Received for publication January 26, 1943)

By methods previously described (1), the lipids of the serum were measured on 142 occasions in 54 patients with glomerular nephritis, in one stage or another. In addition, a large number of measurements were made on patients with other types of renal disorders and with cardiovascular diseases with hypertension.

Cholesterol was fractionated 19 times in sera from 8 patients with extreme hypercholesterolemia. In only one of the 4 , an old man with a nephrotic syndrome and exfoliative dermatitis, did the ratio of free to total cholesterol depart radically from the normal. On one occasion, in another case, also complicated by exfoliative dermatitis, a ratio of 0.36 was observed. The number of observations is too small to warrant generalization. The results do indicate, however, that the cholesterol ratio does not regularly depart from the normal limits (free: total $=0.24$ to 0.32 ) in nephritic hypercholesterolemia.

Of the 54 nephritic patients, 19 had cholesterols greater than $400 \mathrm{mgm}$. per cent at some time. In one of these, cholesterol rose to abnormal heights only after total thyroidectomy. Although the others all had symptoms and signs usually associated with the nephrotic syndrome, a large proportion could not be placed in the categories of nephrosis or the nephrotic phase of glomerulonephritis. In 10 of the 18, edema, profuse albuminuria, and hypoproteinemia were accompanied by signs of renal insufficiency. Some had definite azotemia, 9 had hypertension, 2 were in advanced stages of progressive nephritis, and one was in an exacerbation that proved rapidly fatal. Serum cholesterol greater than $400 \mathrm{mgm}$. per cent was also observed in one patient with Hodgkin's disease and amyloidosis, and in another with diabetes, hypertension, profuse albuminuria, and the other

1 This investigation was aided by grants from the Knight Fund and the Fluid Research Fund of the Yale University School of Medicine. signs and symptoms described by Kimmelstiel and Wilson (5) in patients with intercapillary glomerular sclerosis.

The hypercholesterolemia bore no consistent relation to any single phenomenon of the disease. It was encountered most frequently in the presence of edema and, in certain instances, appeared to vary with the degree of water retention, but there was no consistency about this relation. In one case, for example, when a patient received ammonium nitrate and edema disappeared, cholesterol fell from 340 to $185 \mathrm{mgm}$. per cent. In another, however, while edema increased, cholesterol fell from 375 to $281 \mathrm{mgm}$. per cent. In another instance (see Figure 1), in the face of

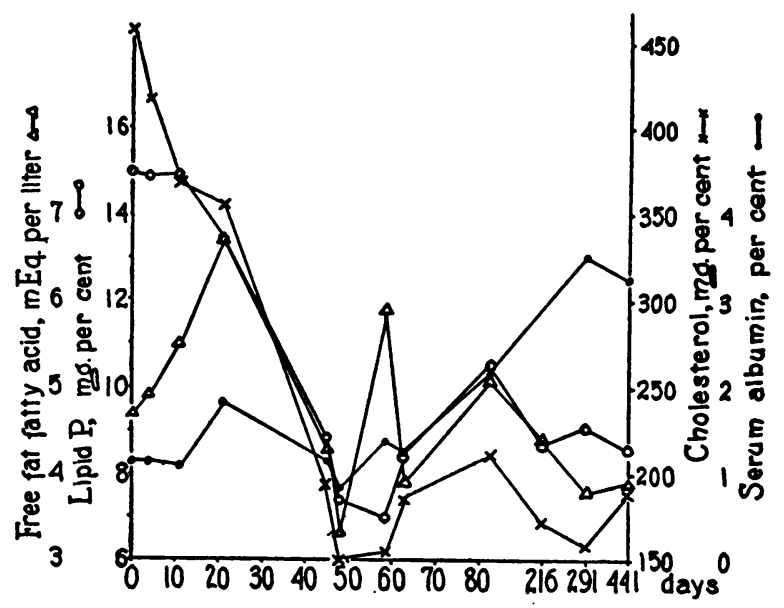

Fig. 1. The Variations of Lipids and Albumin in the Serum of a Patient with Glomerulonephrits

For details see text.

persistent, general anasarca, cholesterol fell from 466 to $150 \mathrm{mgm}$. per cent. When elimination of edema signalizes regression of the disease, cholesterol naturally returns to normal. It also drops, sometimes even further, in the terminal stages of nephritis when renal function is extremely reduced, even if edema persists or recurs. This has been noted by previous observers (2). In addi- 


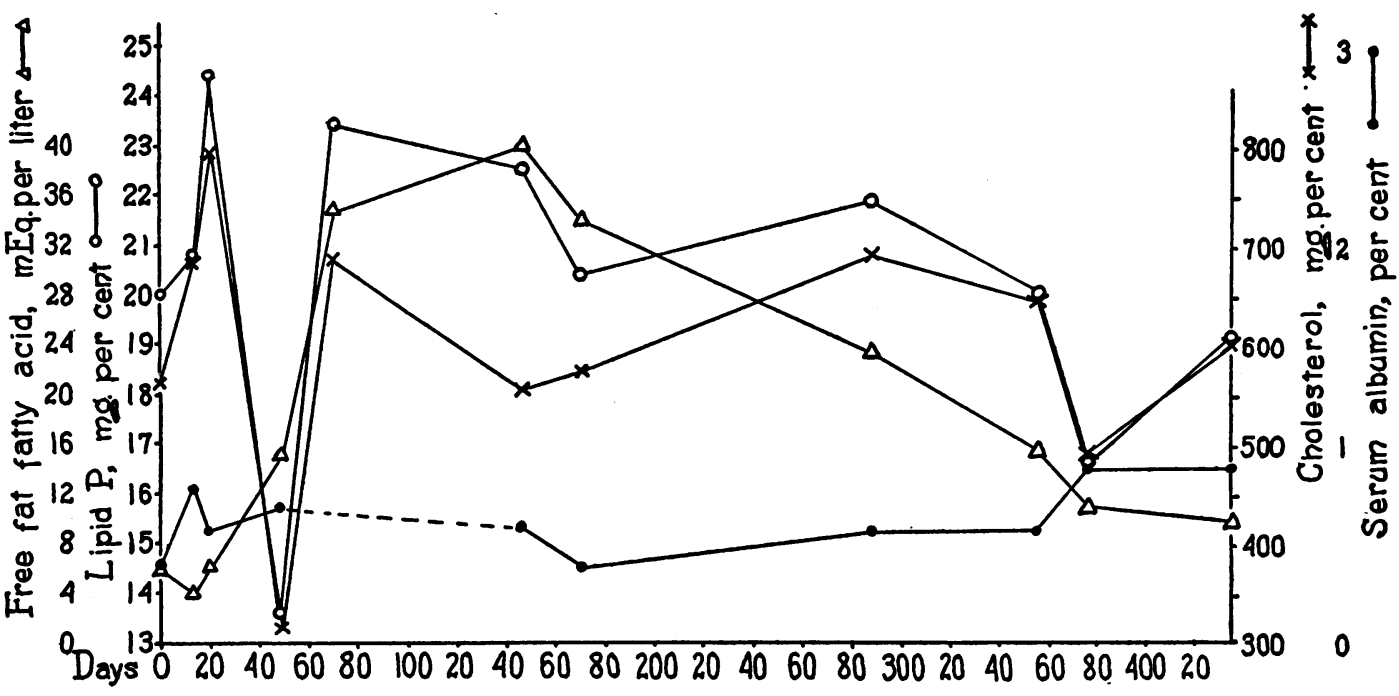

Fig. 2. The Variations of Lipids and Albumin in the Serum of a Patient with Glomerulonephritis

For details see text

tion, it may fluctuate greatly in the active nephrotic phases of nephritis.

Two illustrations of such fluctuations have already been presented; certain others deserve mention. In a boy, 4 years old (see Figure 2), with a nephrotic syndrome and extreme hypoproteinemia, the serum cholesterol on June 20 was only 315 mgm. per cent, although it was 792 and 685 mgm. per cent on May 22 and July 11, respectively. The low concentration occurred when the patient was vomiting and completely unable to take food as the result of a large dose of theophylline which did not induce diuresis. A man, 54 years old (see Figure 3 ), was admitted in an

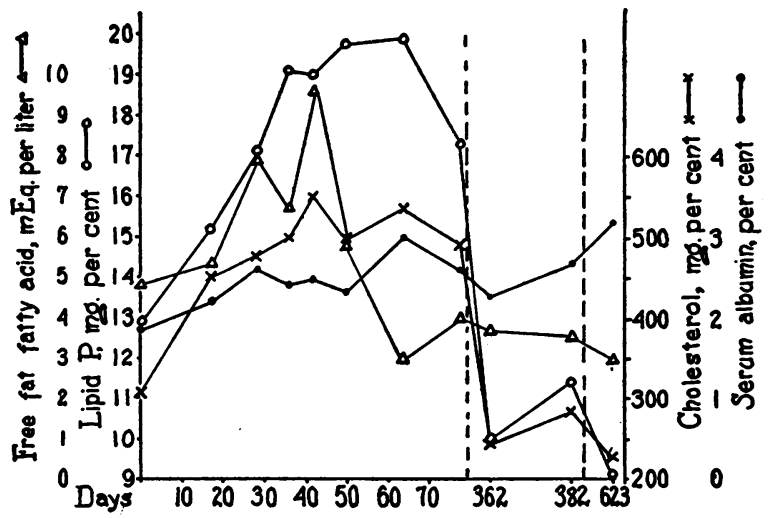

Fig. 3. The Variations of Lipids and Albumin in the Serum of a Patient with Glomerulonephritis For details see text. exacerbation of a chronic glomerular nephritis of 2 years' standing, with a serum cholesterol of 305 mgm. per cent. With improvement, the cholesterol rose to $547 \mathrm{mgm}$. per cent, although the edema diminished. Subsequently, as the nephritis increased in severity, the cholesterol fell gradually to $227 \mathrm{mgm}$. per cent.

The records of the cases suggest that malnutrition or inadequate diet may be one of the factors responsible for these declines of cholesterol. In the instances mentioned, the exacerbations or complications invariably destroyed appetite and usually provoked vomiting. A women of 54 (see Figure 4) with diabetes, hypertension, profuse albuminuria, and general anasarca, when admitted to the hospital, had a serum cholesterol of 358 mgm. per cent. During the next month, she so suffered from anorexia and vomiting that she seldom took more, and usually less, than 1000 Calories a day. Under these conditions, the cholesterol fell to $122 \mathrm{mgm}$. per cent. Subsequently, however, as she became able to take and to retain 2000 Calories or more per day, the cholesterol rose to more than $600 \mathrm{mgm}$. per cent, and remained at this level, even when her edema diminished.

Hiller, Linder, Lundsgaard, and Van Slyke (6) demonstrated that the fatty acids in the blood of patients with nephritic hyperlipemia rose excessively after meals, proving that the blood lipids of these subjects are peculiarly sensitive to dietary 


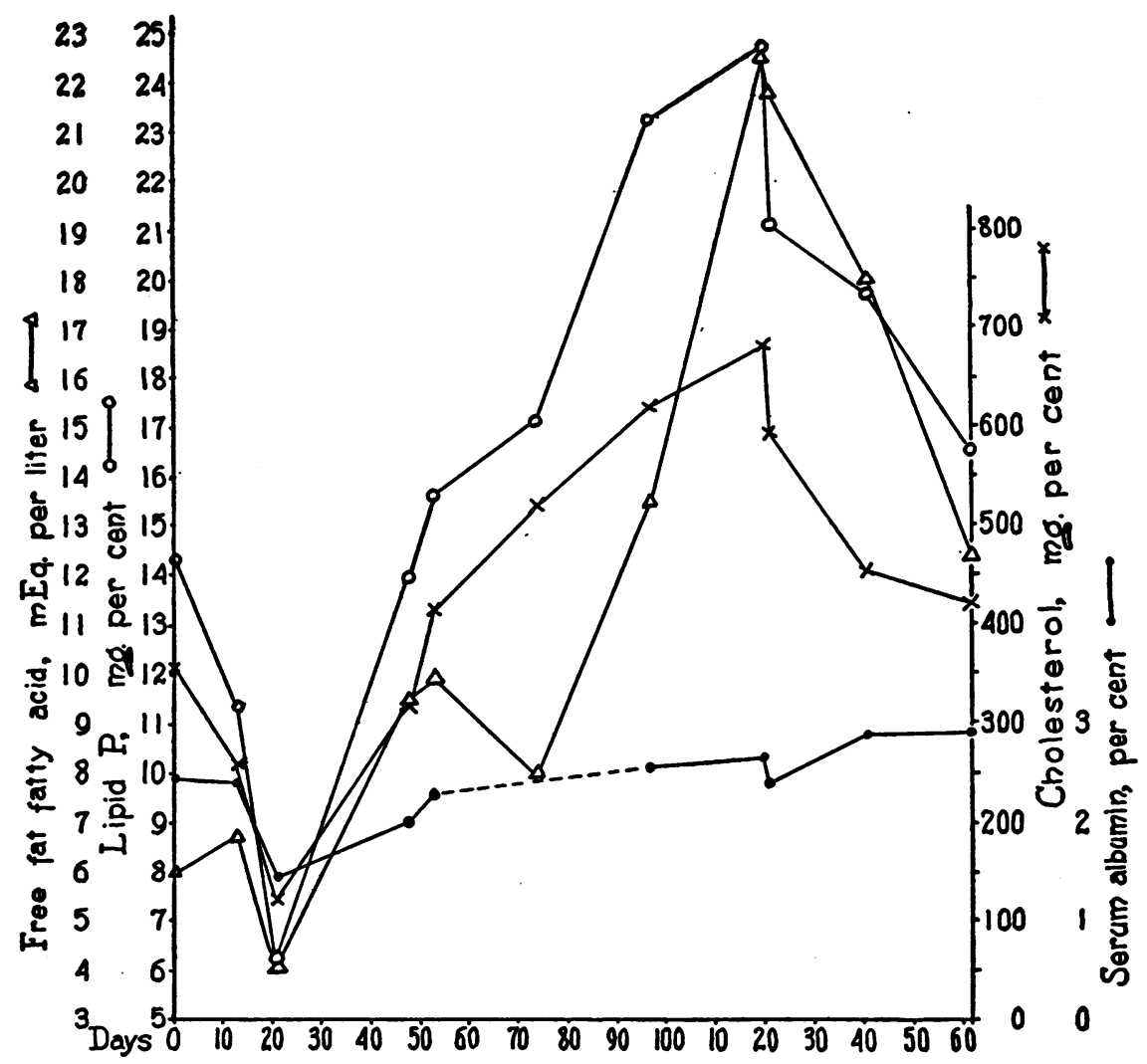

Fig. 4. The Variations of Lipids and Albumin in the Serum of a Patient with Diabetes, Profuse Albuminuria, Hypertension, and Severe Arterial Disease ("Kimmelstiel-Wilson Syndrome")

For details see text

influences. The alimentary response did not, however, affect cholesterol. Epstein (7) and Page and Farr (8) were unable to influence the postabsorptive serum lipids of nephrotic patients by varying the quantity of fat in the diet. These observations do not, however, exclude dietary factors as contributory causes of the hyperlipemia. In myxedema, cholesterol does not participate in alimentary lipemia; but it does rise far above normal concentrations in response to diet. Although the rise of fatty acids after a meal seems to be related to the quantity of fat in the meal, the general level of postabsorptive lipemia appears to depend rather upon the nutritive state of the individual.

Although hypercholesterolemia was most striking in the patients with the greatest deficiency of serum albumin, the irregularity of the correlation with hypoproteinemia, even in renal disease, can be seen from Figure 5. On 9 occasions, in 5 patients, cholesterol was less than $300 \mathrm{mgm}$. per cent when serum albumin was below 2 per cent. At the time, these patients were in advanced stages of renal disease. Since malnutrition lowers both albumin and cholesterol, a general inverse relation between these two functions, such as was suggested by Fishberg (9) and by Barker and Kirk (10), obviously cannot obtain. There is no better correlation with the intensity of proteinuria. One patient with nephritis of some years' standing, which had passed through a long nephrotic stage, had a serum cholesterol that only once in 21 observations in 2 years rose above 350 to $367 \mathrm{mgm}$. per cent, although she excreted in the urine daily 12 to 26 grams of protein. As Epstein (11) first pointed out, the basal metabolism is often low in patients with nephritic lipemia. A cholesterol of $645 \mathrm{mgm}$. per cent was, however, observed in one case of this series when the basal metabolism was - 4 per cent. In another patient, with acute nephritis, cholesterols of 225 and $207 \mathrm{mgm}$. per 
cent were associated with basal metabolisms of -28 and -20 per cent, respectively.

On the whole, lipid phosphorus paralleled cholesterol closely, maintaining the same relation observed in normal subjects and patients with thyroid disease (12). The chief exception again was the old man with the nephrotic syndrome and dermatitis who also had an abnormal cholesterol partition. In this subject, lipid phosphorus was high in proportion to cholesterol.

Some feature of conditions associated with the type of edema that is usually termed renal, then, appears to contribute a tendency to hyperlipemia. What the factor may be that acts as the immediate stimulus to the hyperlipemia has not been discovered. It cannot be identified with any particular disorder that characterizes these states. It is not justifiable, because the lipemia of nephritis resembles in many respects that of myxedema, to infer that it arises from deficient thyroid function.

In one respect, the lipemia of nephritis differs from that of myxedema. In the former, free fat is more intensely and consistently affected. This is illustrated in Figure 6. It is quite clear from this figure, however, that fat does not, like lipid phosphorus, parallel cholesterol at all closely. During states of sustained hypercholesterolemia, fat is usually abnormally high, but fluctuates more than cholesterol does. At times, the two even vary inversely over short periods, as in the course of the case shown in Figure 2. Fat at first was only slightly elevated, although cholesterol was already extremely high. The first sharp rise of fat coincided with a sudden drop of cholesterol during a period of vomiting and severe anorexia. This may represent a reaction to starvation. Thereafter, however, when cholesterol rose again, fat ascended with it to new high levels. Towards the end of the pictured course, it again fell to more moderate concentrations when the patient developed 'otitis media.

It has been claimed that in chronic hemorrhagic nephritis, fat and lipid phosphorus are often considerably elevated, while cholesterol is usually normal or even subnormal $(2,4)$. In the present series, discrepancies between cholesterol and lipid phosphorus were seldom observed (see above). On the other hand, free fat was often moderately increased when cholesterol was normal or even low. This occurred usually in advanced stages of nephritis when patients were desperately ill, commonly when they were vomiting and unable to take food. Again, this may represent merely the mobilization of fat in response to the demands imposed by starvation.

In those conditions which correspond to the picture usually termed nephrosclerosis, in which hypertension and arterial phenomena predominate, while manifestations of renal disease are relatively slight, cholesterol was usually normal or low, con-

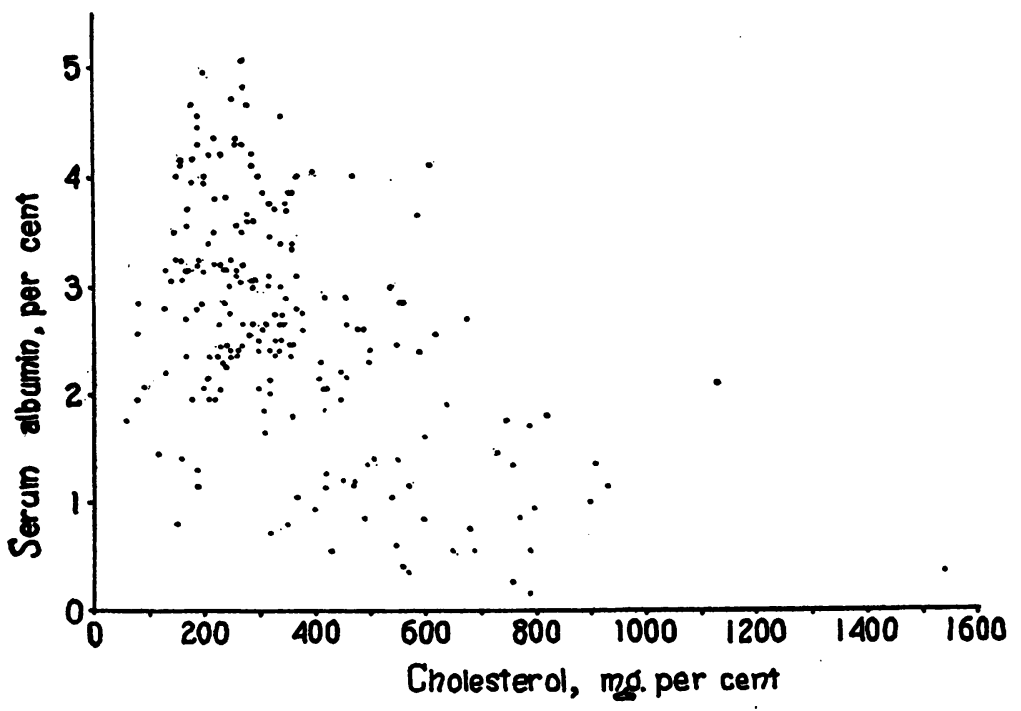

Fig. 5. The Relation of Serum Cholesterol to Serum Albumin in Patients with Renal Disease 


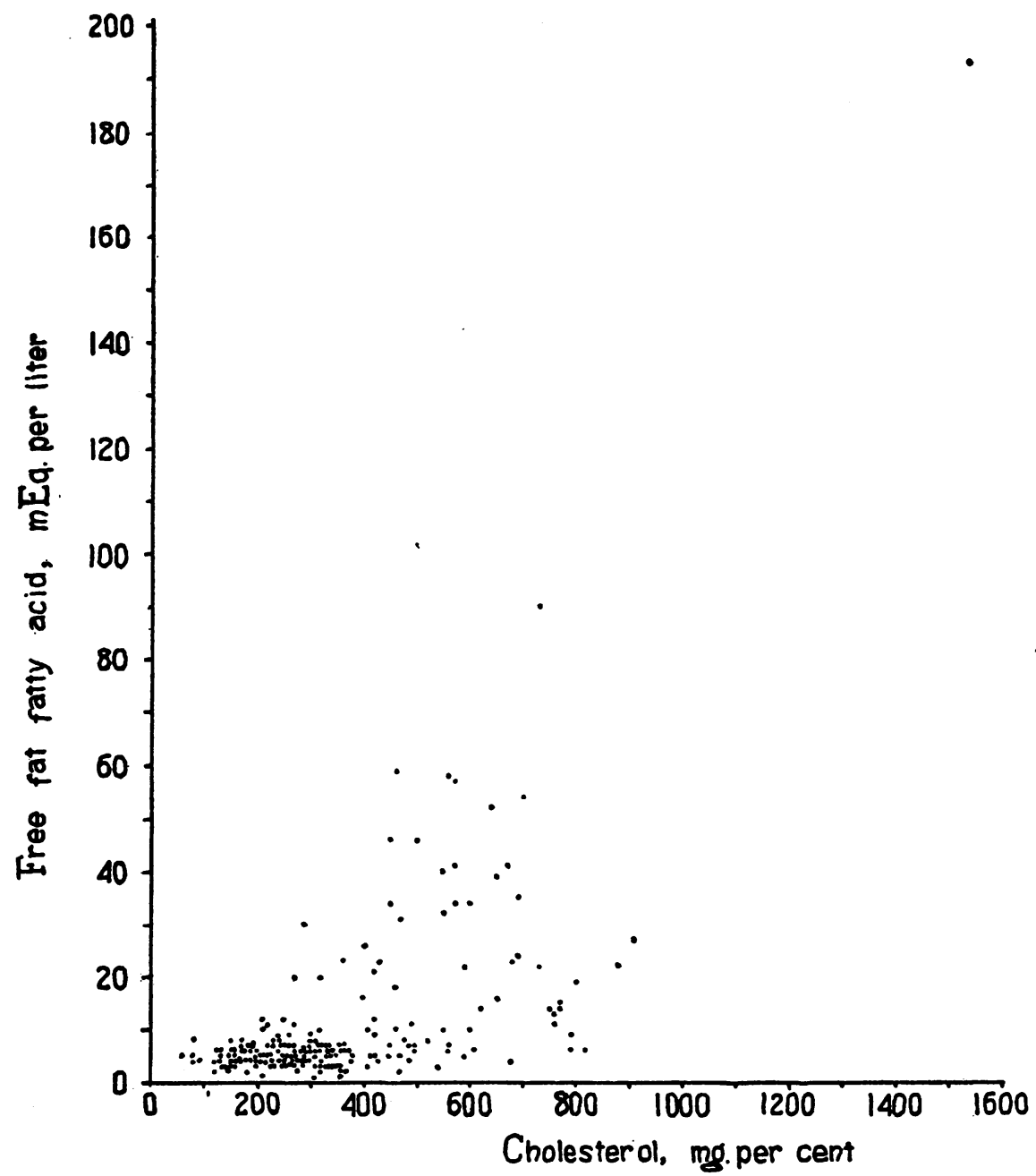

Fig. 6. The Relation of Cholesterol to Neutral Fat in the Serum of Patients with Renal Disease

firming previous observations (3). The ratio of cholesterol to lipid phosphorus was also normal. There was nothing extraordinary about the concentrations of neutral fat, which varied, in 24 observations on 8 such patients, from 1.8 to 8.5 m.eq. of fatty acid per liter, averaging 4.8 .

\section{SUMMARY AND CONCLUSIONS}

The lipids of the serum of a number of patients with diseases of the kidneys have been analyzed.

Cholesterol is frequently elevated in the serum of patients with renal disease, characterized by edema associated with hypoproteinemia, whether they have a true nephrotic syndrome or not. It is impossible as yet to correlate the hypercholesterolemia with any single feature of these diseases.
The partition of cholesterol is not regularly distorted in these conditions.

The relation of cholesterol to lipid phosphorus usually is not disturbed, following the same course which has been described for normal persons and patients with diseases of the thyroid.

Both cholesterol and lipid phosphorus fall when the renal disease clears up or when renal failure develops. They may also fall during exacerbations or other complications that interfere with feeding and impair nutrition.

Neutral fat is usually distinctly elevated when there is hypercholesterolemia.

In a group of patients with arterial disease and hypertension, without evidence of antecedent renal disease, the concentrations and proportions of 
cholesterol, lipid phosphorus, and neutral fat were normal.

\section{BIBLIOGRAPHY}

1. Peters, J. P., and Man, E. B., The interrelations of serum lipids in normal persons. J. Clin. Invest., 1943, 22,

2. Page, I. H., Kirk, E., and Van Slyke, D. D., Plasma lipids in chronic hemorrhagic nephritis. J. Clin. Invest., 1936, 15, 101.

3. Page, I. H., Kirk, E., and Van Slyke, D. D., Plasma lipids in essential hypertension, Ibid., 109.

4. Peters, J. P., and Van Slyke, D. D., Quantitative Clinical Chemistry. Interpretations. Williams and Wilkins, Baltimore, 1931.

5. Kimmelstiel, $P$., and Wilson, C., Intercapillary lesions in the glomeruli of the kidney. Am. J. Path., 1936, $12,83$.

6. Hiller, A., Linder, G. C., Lundsgaard, C., and Van Slyke, D. D., Fat metabolism in nephritis. J. Exper. Med., 1924, 39, 931.
7. Epstein, A. A., Further observations on the nature and treatment of chronic nephrosis. 'Am. J. M. Sc., 1922, 163, 167.

8. Page, I. H., and Farr, L. E., The influence of high and low fat diets and thyroid substance on plasma lipids of nephrotic patients. J. Clin. Invest., 1936, $15,181$.

9. Fishberg, E. H., The relation of the serum proteins and lipids to the osmotic pressure. J. Biol. Chem., 1929, 81, 205.

10. Barker, M. H., and Kirk, E. J., Experimental edema (nephrosis) in dogs in relation to edema of renal origin in patients. Arch Int. Med., 1930, 45, 319.

11. Epstein, A. A., and Lande, H., Studies on blood lipoids. I. The relation of cholesterol and protein deficiency to basal metabolism. Arch. Int. Med., 1922, 30, 563.

12. Peters, J. P., and Man, E. B., The interrelation of serum lipids in patients with thyroid disease. $\mathrm{J}$. Clin. Invest., 1943, 22, . 